\title{
Testosterone induces cardiomyocyte hypertrophy through mammalian target of rapamycin complex 1 pathway
}

\author{
Francisco Altamirano ${ }^{1,2}$, César Oyarce ${ }^{1,2}$, Patricio Silva ${ }^{1,2}$, Marcela Toyos ${ }^{1,2}$, Carlos Wilson ${ }^{1,2}$, \\ Sergio Lavandero ${ }^{1,2,3}$, Per Uhlén ${ }^{4}$ and Manuel Estrada ${ }^{1,2}$ \\ ${ }^{1}$ Facultad de Medicina, Instituto de Ciencias Biomédicas, ${ }^{2}$ Centro FONDAP Estudios Moleculares de la Célula and ${ }^{3}$ Facultad de Ciencias Químicas y \\ Farmacéuticas, Universidad de Chile, Avenida Independencia 1027, Santiago 8380453, Chile \\ ${ }^{4}$ Department of Medical Biochemistry and Biophysics, Karolinska Institutet, Stockholm SE-17177, Sweden \\ (Correspondence should be addressed to M Estrada at Facultad de Medicina, Instituto de Ciencias Biomédicas, Universidad de Chile; \\ Email: iestrada@med.uchile.cl)
}

\begin{abstract}
Elevated testosterone concentrations induce cardiac hypertrophy but the molecular mechanisms are poorly understood. Anabolic properties of testosterone involve an increase in protein synthesis. The mammalian target of rapamycin complex 1 (mTORC1) pathway is a major regulator of cell growth, but the relationship between testosterone action and mTORC1 in cardiac cells remains unknown. Here, we investigated whether the hypertrophic effects of testosterone are mediated by mTORC1 signaling in cultured cardiomyocytes. Testosterone increases the phosphorylation of mTOR and its downstream targets 40S ribosomal protein S6 kinase 1 (S6K1; also known as RPS6KB1) and eukaryotic initiation factor 4E-binding protein 1 (4E-BP1). The S6K1 phosphorylation induced by testosterone was blocked by rapamycin and small interfering RNA to mTOR. Moreover, the hormone increased both extracellular-regulated kinase (ERK1/2) and
\end{abstract}

protein kinase B (Akt) phosphorylation. ERK1/2 inhibitor PD98059 blocked the testosterone-induced S6K1 phosphorylation, whereas Akt inhibition (Akt-inhibitor-X) had no effect. Testosterone-induced ERK1/2 and S6K1 phosphorylation increases were blocked by either 1,2-bis(2aminophenoxy)ethane- $N, N, N, N$-tetraacetic acid-acetoxymethylester or by inhibitors of inositol 1,4,5-trisphosphate $\left(\mathrm{IP}_{3}\right)$ pathway: U-73122 and 2-aminoethyl diphenylborate. Finally, cardiomyocyte hypertrophy was evaluated by, the expression of $\beta$-myosin heavy chain, $\boldsymbol{\alpha}$-skeletal actin, cell size, and amino acid incorporation. Testosterone increased all four parameters and the increase being blocked by mTOR inhibition. Our findings suggest that testosterone activates the mTORC1/S6K1 axis through $\mathrm{IP}_{3} / \mathrm{Ca}^{2+}$ and MEK/ERK1/2 to induce cardiomyocyte hypertrophy.

Journal of Endocrinology (2009) 202, 299-307

\section{Introduction}

The heart is a target tissue for anabolic/androgenic steroids, testosterone being the main physiological hormone (Muller et al. 2003). Testosterone and its synthetic cognates have been used both clinically and illicitly to increase muscle mass (Evans 2004). Exogenously administrated, elevated testosterone concentrations induce cardiac hypertrophy in vitro (Marsh et al. 1998) and in vivo (Cabral et al. 1988, Malhotra et al. 1990, Nahrendorf et al. 2003), but the molecular mechanisms are still poorly understood. Protein synthesis is essential for both normal and hypertrophic growth of cardiomyocytes (Hannan et al. 2003). In cardiac cells, protein synthesis is highly regulated by the mammalian target of rapamycin complex 1 (mTORC1), which stimulates protein translation and ribosome biosynthesis (Proud 2004). mTORC1 lies upstream of critical translation regulators such as the $40 \mathrm{~S}$ ribosomal protein S6 kinase 1 (S6K1; also known as RPS6KB1) and the eukaryotic initiation factor 4E-binding protein 1 (4E-BP1;
Proud 2004). Activation of the mTORC1 pathway is a critical step to induce cardiac hypertrophy in vitro (Takano et al. 1996, Boluyt et al. 1997, Simm et al. 1998, Rolfe et al. 2005, Kenessey \& Ojamaa 2006) and in vivo (Shioi et al. 2003, McMullen et al. 2004, Gao et al. 2006, Kuzman et al. 2007, Kemi et al. 2008). Pro-hypertrophic stimuli can regulate mTORC1 signaling, mainly activating either the phosphatidylinositol 3-kinase (PI3K)/Akt (Shioi et al. 2002, Kenessey \& Ojamaa 2006) or the MEK/extracellular signal-regulated kinase 1/2 (ERK1/2) pathways (Wang \& Proud 2002, Rolfe et al. 2005). Increased protein synthesis is a hallmark event for anabolic action of testosterone, but the relationship with mTORC1 is unknown. Here, we show that testosterone activates the mTORC1 pathway in cardiomyocytes through inositol 1,4,5-trisphosphate $\left(\mathrm{IP}_{3}\right)$-mediated $\mathrm{Ca}^{2+}$ release and MEK/ERK1/2. Moreover, inhibition of mTORC1 abolished cardiomyocyte hypertrophy induced by testosterone, suggesting an important role of this pathway during the shift from normal to hypertrophied cardiomyocytes. 


\section{Materials and Methods}

\section{Reagents}

Testosterone enanthate, cyproterone acetate, U-73122, 2-aminoethyl diphenylborate (2-APB), pancreatin, and 5-bromo-2-deoxyuridine were purchased from Sigma Chemical Company (St Louis, MO, USA). Rapamycin, Akt-inhibitor-X, and PD98059 were from Calbiochem (San Diego, CA, USA). Of 1,2-bis(2-aminophenoxy)ethane$N, N, N, N$-tetraacetic acid-acetoxymethylester (BAPTA-AM) and cell tracker green were from Molecular Probes, Invitrogen (Eugene, OR, USA). [ $\left.{ }^{3} \mathrm{H}\right]$-leucine was from NEN Radiochemicals Perkin Elmer (Waltham, MA, USA). Collagenase type II was from Worthington Biochemical Corporation (Lakewood, CA, USA). All other reagents were of analytical grade.

\section{Culture of neonatal rat cardiomyocytes}

All procedures for animal use were in accordance with guidelines approved by the Bioethical Committee at the Facultad de Medicina, Universidad de Chile. Primary neonatal rat cardiomyocytes were prepared from hearts of 1-3 days old Sprague-Dawley rats as previously described (Vicencio et al. 2006). This protocol produces cultures of cardiomyocytes that are at least 95\% pure (Vicencio et al. 2006). To prevent overgrowth of fibroblasts and smooth muscle cells, $10 \mu \mathrm{M}$ bromodeoxyuridine was used in the cell culture medium. Cardiomyocytes were cultured in a medium containing DMEM:M-199 (4:1) supplemented with 10\% FBS and 1\% penicillin-streptomycin.

\section{siRNA transfection}

Small interference RNA to mTOR (siRNA-mTOR) was obtained from Cell Signaling Technology (catalog number \#6381, Danvers, MA, USA). After $24 \mathrm{~h}$ of cultures, cells grown on $60 \mathrm{~mm}$ dishes were transfected with siRNAmTOR (50 nM) using Lipofectamine 2000 (Invitrogen) according to the manufacturer's instructions. The knockdown of $\mathrm{mTOR}$ protein expression was confirmed by western blot.

\section{Western blot}

Cardiomyocytes were grown on $60 \mathrm{~mm}$ dishes and serum starved for $24 \mathrm{~h}$ before being exposed to testosterone for various times. The experimental procedure for western blot and cell lysates has been previously described (Estrada et al. 2003). Briefly, equal amounts of proteins were separated in SDS-PAGE polyacrylamide gels, and then transferred to nitrocellulose membranes. The following primary antibodies and their dilutions were used: anti-p-mTOR (1:1000; Cell Signaling); anti-mTOR (1:1000; Cell Signaling); anti-p-S6K1 (1:1,000; Upstate); anti-S6K1 (1:1000; Upstate); anti-p-4E-BP1 (1:1000; Cell Signaling); anti-p-Akt
(1:1000; BD Bioscience); anti-Akt (1:1000; Santa Cruz, Santa Cruz, CA, USA); anti-p-ERK1/2 (1:1000; Cell Signaling); and anti-ERK1/2 (1:1000; Santa Cruz); anti- $\beta$-myosin heavy chain ( $\beta$-MHC) (1:10 000, Sigma); anti-skeletal actin (SKA) (1:2000, Sigma); and anti- $\beta$-actin (1:10 000, Sigma). The protein bands in the blots were visualized using an ECL detection kit (Pierce, Piscataway, NY, USA) and the intensity of the bands was determined by scanning densitometry.

\section{Cell size measurements}

Cardiomyocytes were cultured for $24 \mathrm{~h}$. Thereafter, the culture medium was replaced with a medium supplemented with testosterone and/or rapamycin and cultured for additional $48 \mathrm{~h}$. To quantify the cell size changes induced by the hormone, cardiomyocytes were incubated with the vital fluorescent dye cell tracker green (Molecular Probes) for $45 \mathrm{~min}$. Acquired confocal fluorescence images (LSM Pascal 5, Zeiss, Oberkochen, Germany) were analyzed and compared using the Image J Software (Bethesda, MA, USA). At least eight different fields from three independent cultures to each condition ( $>100$ cells) were determined.

\section{Aminoacid incorporation}

After $24 \mathrm{~h}$ of culture, cardiomyocytes were incubated with $\left[{ }^{3} \mathrm{H}\right]$-leucine $(2.5 \mu \mathrm{Ci} / \mathrm{ml}$; NEN $)$ for additional $48 \mathrm{~h}$ in the presence or absence of testosterone. Next, the cells were washed four times with ice-cold PBS and treated with $10 \%$ trichloroacetic acid at $4{ }^{\circ} \mathrm{C}$ for $1 \mathrm{~h}$. The samples were centrifuged for $20 \mathrm{~min}$ at $16000 \mathrm{~g}$, and the pellets were washed once with ice-cold absolute acetone and dissolved in $0 \cdot 2 \mathrm{M} \mathrm{NaOH}$ (Kenessey \& Ojamaa 2006). Aliquots of triplicate samples per group were counted in a liquid scintillation counter (Beckman Instruments, Fullerton, CA, USA). The data correspond to the ratio of basal counts/min with respect to each experimental condition.

\section{Statistical analysis}

Results are expressed as mean \pm s.E.M. In order to compare the difference between basal and post-stimulated conditions we carried out ANOVAs and the statistical a differences were determined by Tukey's post-test. A value of $P<0.05$ was considered statistically significant.

\section{Results}

Testosterone activates mTORC1 pathway in cultured cardiomyocytes

Since mTORC1 is a major regulator of cell growth through its downstream targets S6K1 and 4E-BP1, we evaluated the phosphorylation changes of mTOR ( $\left.\mathrm{Ser}^{2448}\right)$, S6K1 $\left(\mathrm{Thr}^{389}\right)$, and $4 \mathrm{E}-\mathrm{BP} 1\left(\mathrm{Ser}^{65}\right)$ induced by testosterone in cardiomyocytes 
(Fig. 1). These phosphorylation sites are well recognized for their ability to reflect the actual mTORC1 activity (Wang \& Proud 2007). Testosterone (100 nM) increased the mTOR phosphorylation in a biphasic manner with an initial increase
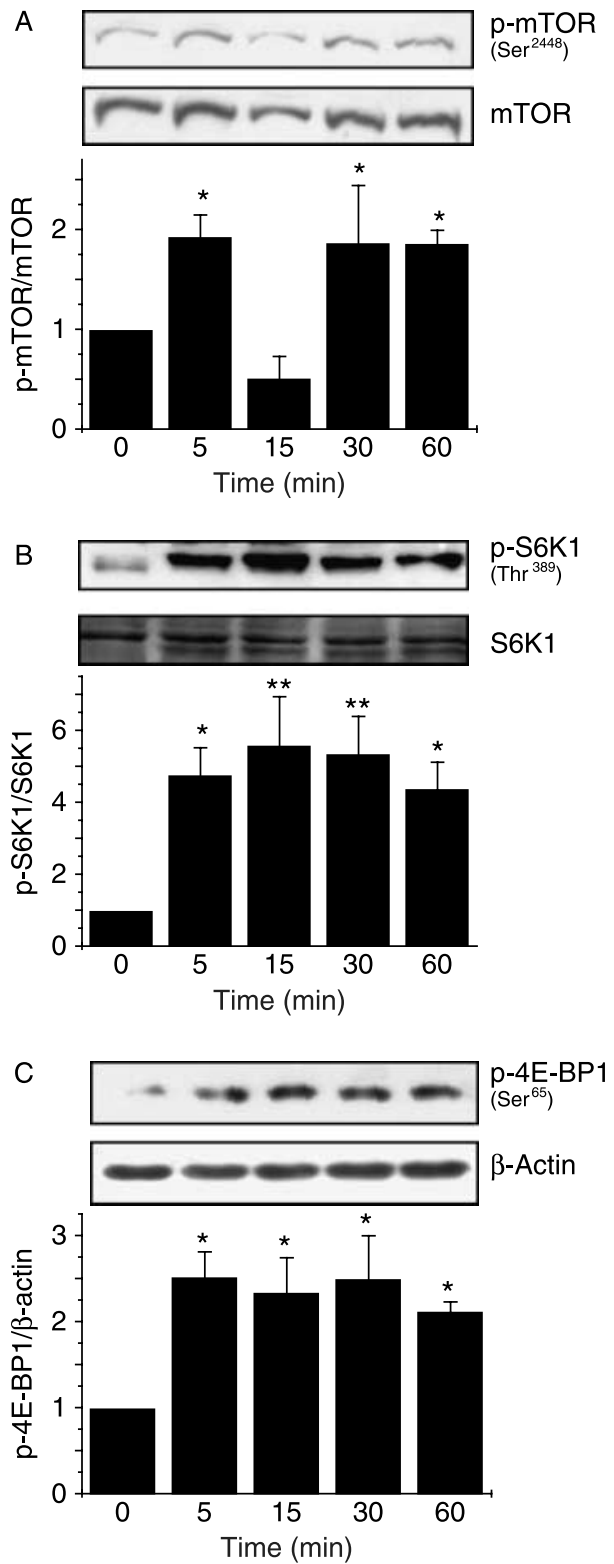

Figure 1 Testosterone activates mTORC1, S6K1, and 4E-BP1 in cultured cardiomyocytes. Cells were stimulated with testosterone (100 nM) for 5, 15, 30, or 60 min. Phosphorylated mTOR (Panel A), S6K1 (Panel B), and 4E-BP1 (Panel C) levels were determined by western blot from whole cell lysates, using specific antibodies against the active phosphorylated proteins. mTOR and S6K1 phosphorylation were re-probed and normalized with their respective total protein, whereas $4 \mathrm{E}-\mathrm{BP} 1$ was normalized with $\beta$-actin. Densitometric analyses show the ratio of phosphorylated and total proteins. Values are mean \pm s.E.M. $(n=3$ to each condition). ${ }^{*} P<0 \cdot 05,{ }^{* *} P<0 \cdot 01$ compared with the basal value. at $5 \mathrm{~min}$ which was approximately twofold the basal value $(P<0 \cdot 05, n=3)$ followed by a similar phosphorylation increase after $30 \mathrm{~min}$, which was sustained for the studied times (Fig. 1A). Furthermore, phosphorylation of both S6K1 (Fig. 1B, $15 \mathrm{~min}, P<0 \cdot 01, n=3$ ) and 4E-BP1 (Fig. 1C, $5 \mathrm{~min}$, $P<0 \cdot 05, n=3)$ were also increased. These data indicate that testosterone induces full activation of the mTORC1 pathway in cardiomyocytes.

S6K1 was evaluated next because phosphorylation changes in this protein reflect mTORC1 activation (Wang \& Proud 2007). The activity of this complex can be blocked by the immune-suppressants macrolide and rapamycin (Chen et al. 1995). Figure 2 shows that testosterone-induced S6K1 phosphorylation increase was blocked by $20 \mathrm{nM}$ rapamycin (Fig. 2A, $P<0 \cdot 01, n=4$ ). To further determine the direct action of mTORC1 on S6K1, we used small interference RNA to mTOR (siRNA-mTOR). In cardiomyocytes transfected with siRNA-mTOR the expression of mTOR
A

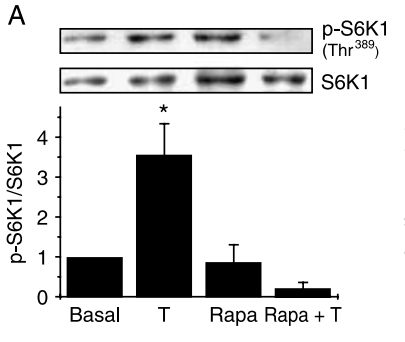

C
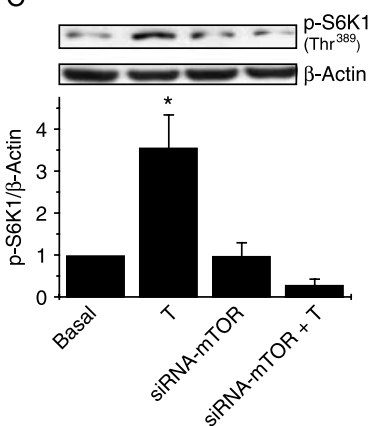

B

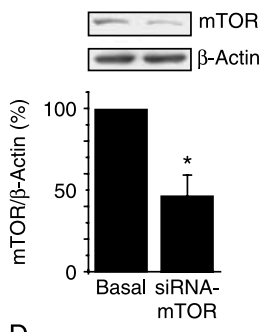

D
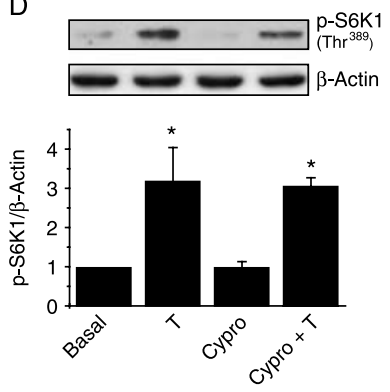

Figure 2 Effect of mTORC1 inhibition on testosterone-induced S6K1 phosphorylation in cultured cardiomyocytes. Cells were preincubated with rapamycin (rapa, $20 \mathrm{nM}$ ) for $30 \mathrm{~min}$ and then stimulated with testosterone (T, $100 \mathrm{nM})$ for $15 \mathrm{~min}$ (time for the S6K1 phosphorylation peak). (Panel A) Representative western blot and densitometric analysis showing the inhibitory effects of rapamycin on S6K1 phosphorylation $(n=4)$. (Panel B) Cells transiently transfected with siRNA-mTOR exhibit $\sim 53 \%$ reduced protein expression with respect to non-transfected cells $(n=3)$. (Panel C) The increase in the S6K1 phosphorylation induced by testosterone was inhibited by mTOR knockdown $(n=3)$. (Panel D) Cells were pre-incubated with cyproterone (Cypro, $1 \mu \mathrm{M}, n=4)$ for $30 \mathrm{~min}$ followed by stimulation with testosterone ( $\mathrm{T}, 100 \mathrm{nM})$ for $15 \mathrm{~min}$. The inhibition of androgen receptor did not modify the S6K1 phosphorylation increase induced by testosterone. Values are mean \pm S.E.M. ( $n=3$ to each condition). ${ }^{*} P<0 \cdot 05$, compared with basal value. 
protein was reduced by $53 \%$ (Fig. $2 \mathrm{~B}, P<0 \cdot 05, n=3$ ). In addition, knockdown of mTOR inhibited the testosteroneinduced S6K1 phosphorylation increase (Fig. 2C, $P<0 \cdot 05$, $n=3)$. Taken together, these data suggest a direct effect of mTORC1 on S6K1 phosphorylation in testosteronestimulated cardiomyocytes.

Previously, we have shown that testosterone induces rapid effects independent of its intracellular androgen receptor (AR) in skeletal muscle cells (Estrada et al. 2003), neuroblastoma cells (Estrada et al. 2006), and cardiomyocytes (Vicencio et al. 2006). To study the participation of AR on mTORC1 activation, we performed experiments using cyproterone, an inhibitor of the intracellular AR. Cyproterone $(1 \mu \mathrm{M})$ did not modify the S6K1 phosphorylation increase induced by testosterone (Fig. 2D, $P<0 \cdot 05, n=4$ ). These results suggest that $\mathrm{mTORC1}$ activation by testosterone in cardiomyocytes is both specific and independent of the canonical AR pathway.

\section{Testosterone activates ERK1/2 and Akt}

mTORC1 is a multifunctional protein complex involved in survival, proliferation, differentiation, and growth (Richardson et al. 2004). mTORC1 is activated mainly by the upstream kinases ERK1/2 or Akt (Proud 2004). To explore the mechanism by which testosterone activates mTORC1, we first evaluated whether testosterone can activate these kinases. Testosterone induced an increase in phosphorylation of both ERK1/2 and Akt (Fig. 3). Timecourse analysis for ERK1/2 activation shows a fast and transient peak at 5-15 min (Fig. 3A, $P<0 \cdot 01, n=3$ ), whereas Akt phosphorylation displays a delayed increase, which peaked at $30 \mathrm{~min}$ after testosterone stimulation, returning to basal values after an hour (Fig. 3B, $P<0 \cdot 05, n=3$ ). Phosphorylation kinetics for both ERK1/2 and Akt are in agreement with mTORC1 activation.
ERK1/2, but not Akt, is involved in mTORC1 activation induced by testosterone

In order to determine the upstream signaling pathway involved in mTORC1 activation, we used specific inhibitors for MEK1/2 and Akt. Cardiomyocytes were pre-incubated with $50 \mu \mathrm{M}$ PD98059, a MEK1/2 inhibitor, or with $10 \mu \mathrm{M}$ Akt-inhibitor-X, a specific inhibitor that blocks Akt kinase activity but does not modify PI3K activity (Thimmaiah et al. 2005). Akt inhibition had no effect, whereas ERK1/2 inhibition blocked the testosterone-induced S6K1 phosphorylation (Fig. 3C, $n=4$ ). Together, these results indicate that MEK/ERK1/2 pathway, but not PI3K/Akt, is required for mTORC1 activation and subsequent S6K1 phosphorylation induced by testosterone in cardiomyocytes.

\section{Role of $\mathrm{Ca}^{2+}$ signaling in testosterone-induced ERK1/2} phosphorylation

Rise in intracellular $\mathrm{Ca}^{2+}$ concentration has been suggested as a critical step for ERK1/2 activation (Agell et al. 2002). Previously, we demonstrated that testosterone increases intracellular $\mathrm{Ca}^{2+}$ levels in cardiomyocytes (Vicencio et al. 2006) and skeletal muscle cells (Estrada et al. 2003), through a pertussis toxin (PTX)-sensitive G-protein coupled receptor that activates phospholipase $\mathrm{C}$ (PLC) to generate $\mathrm{IP}_{3}$, which evokes $\mathrm{Ca}^{2+}$ signaling. To determine whether intracellular $\mathrm{Ca}^{2+}$ is involved in the testosterone-induced ERK1/2 phosphorylation, cardiomyocytes were incubated in $\mathrm{Ca}^{2+}$ free medium (1 mM EGTA) or pre-incubated with BAPTAAM (a chelator of intracellular $\mathrm{Ca}^{2+}$ ). As is shown in Fig. 4, ERK1/2 phosphorylation was only blocked by BAPTA-AM (Fig. 4A, $n=3$ ). These observations suggest that $\mathrm{Ca}^{2+}$ release from intracellular stores is necessary for ERK1/2 activation. Next, to investigate the role of $\mathrm{IP}_{3}$ signaling on ERK1/2 phosphorylation induced by testosterone, cardiomyocytes were pre-incubated with PTX (a G-protein
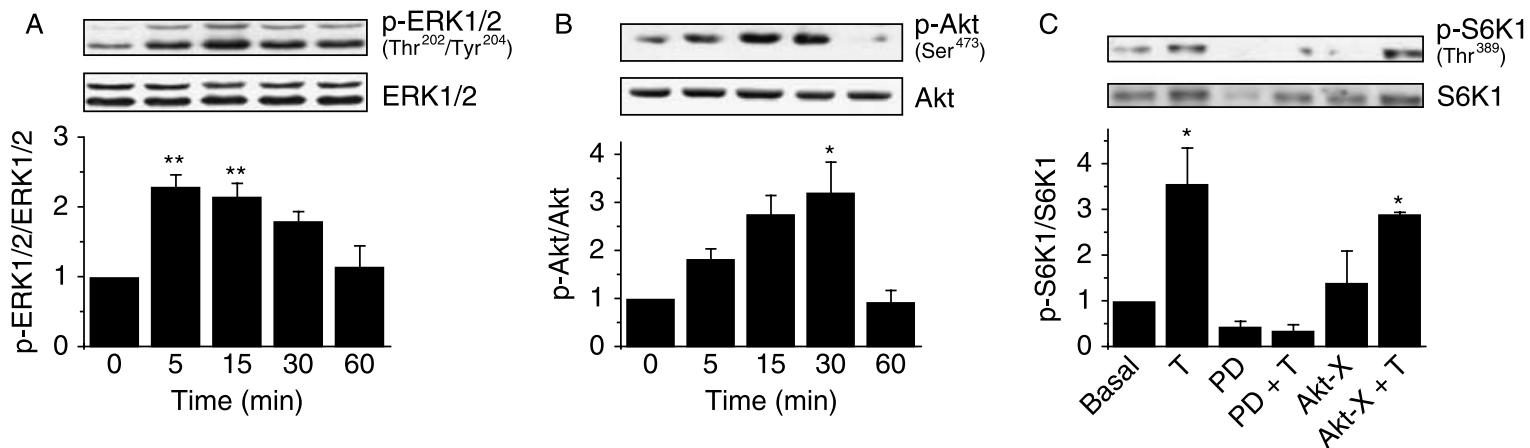

Figure 3 Activation of ERK1/2, but not Akt, is required for mTORC1 activation by testosterone in cultured cardiomyocytes. Timecourse of ERK1/2 and Akt phosphorylation induced by testosterone (T, $100 \mathrm{nM}$ ) in cardiomyocytes. (Panel A) ERK1/2 phosphorylation shows a fast increase at $5 \mathrm{~min}$, returning to basal values after $1 \mathrm{~h}(n=3)$. (Panel B) A delayed increase in the Akt phosphorylation is observed for up to $30 \mathrm{~min}(n=3)$, which returns to basal values after $1 \mathrm{~h}$. (Panel C) Cells were pre-incubated with Akt-inhibitor-X $(A k t-X)$ or PD98059 (PD). Inhibition of ERK1/2 blocked the increase in the S6K1 phosphorylation $(n=4)$. Values are mean \pm s.E.M. ${ }^{*} P<0 \cdot 05,{ }^{* *} P<0 \cdot 01$ compared with basal value. 
A
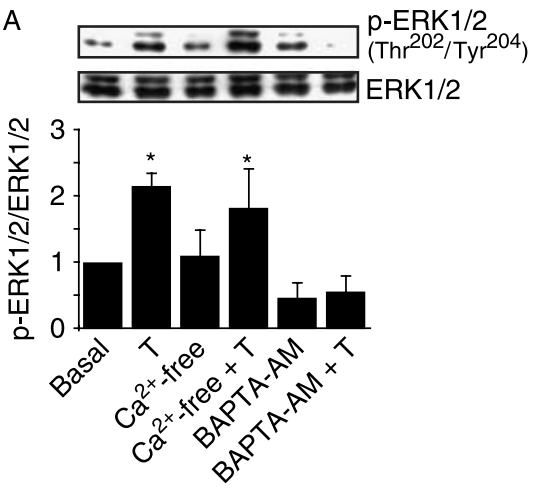

B
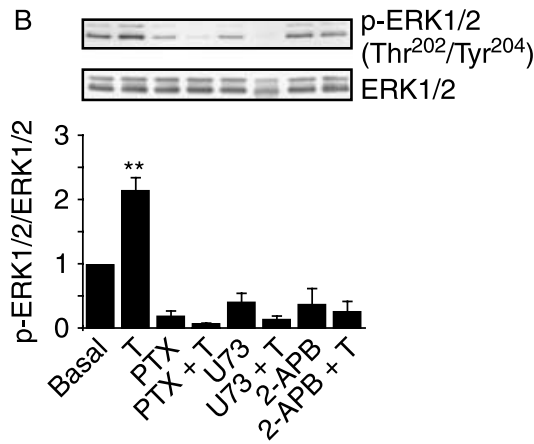

Figure 4 Role of $\mathrm{Ca}^{2+}$ in the testosterone-induced ERK1/2 phosphorylation in cultured cardiomyocytes. (Panel A) Cells were stimulated with testosterone $(\mathrm{T}, 100 \mathrm{nM})$ in $\mathrm{Ca}^{2+}$-free medium (1 mM EGTA) or in the presence of BAPTA-AM $(100 \mu \mathrm{M})$.

Densitometric analysis shows ERK1/2 phosphorylation. (Panel B) Testosterone-induced ERK1/2 phosphorylation was studied in cells pre-incubated with PTX $(1 \mu \mathrm{g} / \mathrm{ml})$ or with the inhibitors of the $\mathrm{IP}_{3}$ pathway: U-73122 (U73, $15 \mu \mathrm{M})$ or 2-APB $(20 \mu \mathrm{M})$. Values are mean \pm s.E.M. ( $n=3$ to each condition). ${ }^{*} P<0 \cdot 05,{ }^{* *} P<0 \cdot 01$ compared with the basal value.

inhibitor) or with the $\mathrm{IP}_{3}$ inhibitors: U-73122 (a PLC inhibitor) or 2-APB (an $\mathrm{IP}_{3} \mathrm{R}$ blocker). All three inhibitors blocked the testosterone-induced ERK1/2 phosphorylation increase (Fig. 4B;n=3). These results suggest a sequence of events involving activation of a PTX-sensitive G-protein, $\mathrm{IP}_{3}$-mediated $\mathrm{Ca}^{2+}$ release, and ERK1/2 phosphorylation.

\section{Testosterone-induced mTORC1 activation is dependent on} intracellular $\mathrm{Ca}^{2+}$ levels

Because the testosterone-triggered ERK1/2 phosphorylation requires intracellular $\mathrm{Ca}^{2+}$, inhibition of $\mathrm{IP}_{3}$-mediated $\mathrm{Ca}^{2+}$ increase should block mTORC1 activation. In order to test this hypothesis, a similar strategy to determine the $\mathrm{Ca}^{2+}$ dependence of ERK1/2 was performed. In $\mathrm{Ca}^{2+}$-free medium, testosterone increased S6K1 phosphorylation, whereas in cardiomyocytes pre-incubated with BAPTAAM, this effect was completely blocked (Fig. 5A, $n=3$ ). To further determine the $\mathrm{Ca}^{2+}$ pool required for mTORC1 activation, cardiomyocytes were incubated with PTX, $\mathrm{U}-73122$ or 2-APB. As expected, inhibition of $\mathrm{IP}_{3}$-signaling blocked the S6K1 phosphorylation increase (Fig. 5B, $n=3$ ). Together, these results indicate that testosterone-induced mTORC1 signaling involve both ERK1/2 and $\mathrm{IP}_{3}$-mediated intracellular $\mathrm{Ca}^{2+}$ increase.

Testosterone-induced cardiomyocyte hypertrophy involves mTORC1

Elevated testosterone concentrations are associated with cardiac hypertrophy in vitro and in vivo (Cabral et al. 1988, Malhotra et al. 1990, Marsh et al. 1998, Nahrendorf et al. 2003). In order to assess if testosterone triggers cardiomyocyte hypertrophy via mTORC1 signaling, we examined different hypertrophy parameters. First, we evaluated testosterone effects on protein expression of $\beta$-MHC and $\alpha$-SKA, which are considered cardiac hypertrophy markers (Frey \& Olson 2003). Stimulation of cardiomyocytes with testosterone for $24 \mathrm{~h}$ increased protein expression by approximately twofold for $\beta$-MHC (Fig. 6A, $P<0 \cdot 01, n=4$ ) and approximately

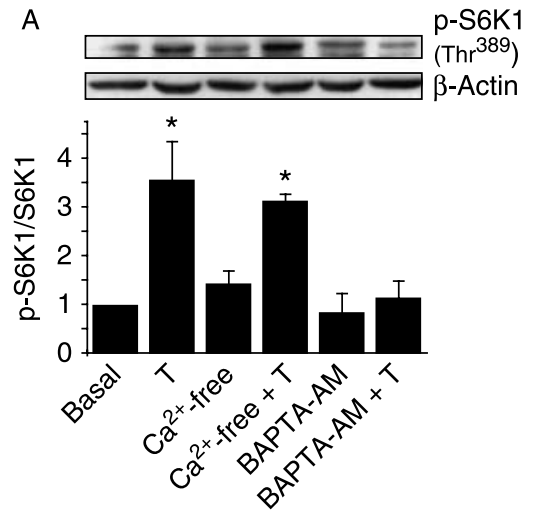

B
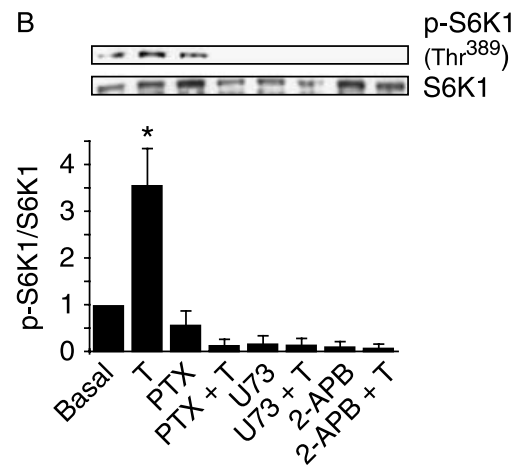

Figure 5 Role of $\mathrm{Ca}^{2+}$ on mTORC1 activation induced by testosterone in cultured cardiomyocytes. (Panel A) Cells were stimulated with testosterone $(\mathrm{T}, 100 \mathrm{nM})$ in $\mathrm{Ca}^{2+}$-free medium (1 mM EGTA) or in the presence of BAPTA-AM $(100 \mu \mathrm{M})$. Densitometric analysis shows S6K1 phosphorylation. (Panel B) Testosterone-induced S6K1 phosphorylation was investigated in cells pre-incubated with PTX $(1 \mu \mathrm{g} / \mathrm{ml})$ or with the inhibitors of the $\mathrm{IP}_{3}$ pathway: U-73122 $(\mathrm{U} 73,15 \mu \mathrm{M})$ or 2 -APB $(20 \mu \mathrm{M})$. Values are mean \pm S.E.M. ( $n=3$ to each condition). ${ }^{*} P<0 \cdot 05$ compared with the basal value. 

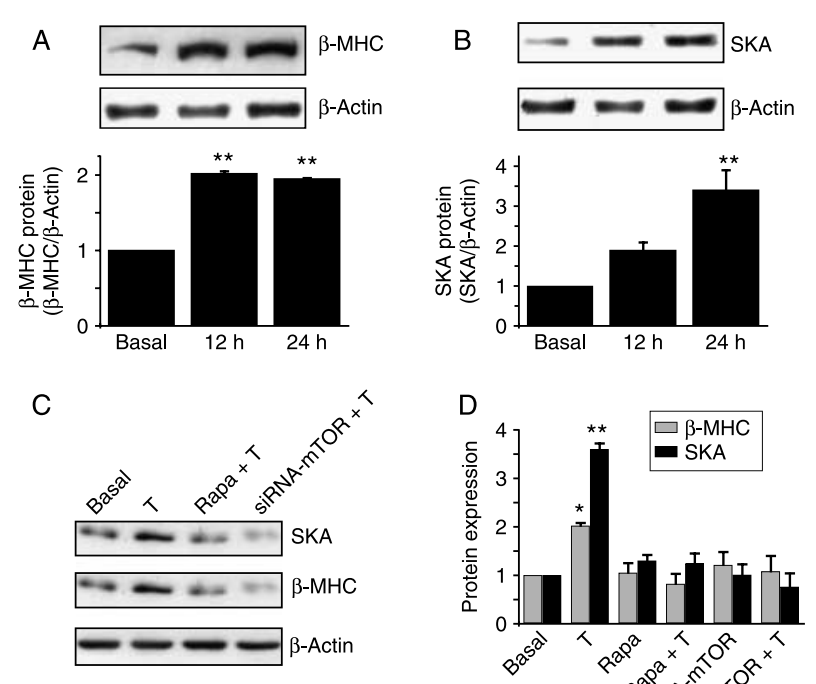

been explained by activation of the intracellular AR (Marsh et al. 1998). Here, we show that in addition to the canonical genomic mechanism, testosterone activates mTORC1 to induce cardiomyocyte hypertrophy. Our data show that cyproterone, an inhibitor of the intracellular AR, did not affect mTORC1 activation induced by testosterone.

Different hypertrophic stimuli can exploit divergent pathways to induce mTORC1-mediated cardiac hypertrophy. Thyroid hormone and physical exercise might activate mTORC1 through PI3K/Akt (Kenessey \& Ojamaa 2006, Kemi et al. 2008), whereas phenylephrine will activate MEK/ERK1/2 (Rolfe et al. 2005). The importance of the MEK/ERK1/2 pathway on development of cardiac hypertrophy has been studied in transgenic mice with cardiacrestricted expression of an activated MEK1 (Bueno et al. 2000). These mice generate a concentric hypertrophy, which demonstrates the hypertrophic role of these signaling

Figure 6 In vitro effect of testosterone and mTORC1 inhibition in cardiomyocyte hypertrophy. (Panels A and B) Cells were stimulated with testosterone (T, $100 \mathrm{nM}$ ) for 12 and $24 \mathrm{~h}$. The expression levels of $\beta-$ MHC (Panel A) and SKA (Panel B) were determined by western blot $(n=4)$. (Panel C) mTORC1 inhibition with rapamycin (rapa, $20 \mathrm{nM}, n=4)$ or siRNA-mTOR $(n=3)$ abolished the testosteroneinduced $\beta-\mathrm{MHC}$ and SKA protein expression increase. (Panel D) Densitometric analysis shows the protein expression for the indicated experimental condition. Values are mean \pm S.E.M. ${ }^{*} P<0 \cdot 05,{ }^{* *} P<0 \cdot 01$ compared with the basal value.

threefold for SKA (Fig. 6B, $P<0 \cdot 01, n=4$ ). Rapamycin blocked the increase in $\beta-\mathrm{MHC}$ and SKA expression triggered by testosterone (Fig. $6 \mathrm{C}$ and $\mathrm{D}, n=4$ ). Moreover, siRNA-mTOR also blocked testosterone-induced increase of these hypertrophic markers, without changes in their basal expression (Fig. 6C and D, $n=3$ ).

Figure $7 \mathrm{~A}$ shows a $26 \%$ increase in cell size following testosterone treatment for $48 \mathrm{~h}$ compared with nonstimulated cells $(P<0 \cdot 01, \sim 100$ cells for each condition). Pre-incubation with rapamycin blocked the cell size increase induced by testosterone. mTORC1 is a critical regulator of protein synthesis. To further assess whether anabolic and hypertrophic effects of testosterone occur through the activation of this pathway, aminoacid incorporation was determined. As shown in Fig. 7B, testosterone increased aminoacid incorporation, which was inhibited by rapamycin $(P<0 \cdot 05 ; n=4)$. These results suggest that activation of mTORC1 signaling pathway plays a critical role in testosterone-induced cardiomyocyte hypertrophy.

\section{Discussion}

This study shows the first evidences that testosterone activates the mTORC1 signaling pathway in cultured neonatal cardiomyocytes. In cardiac cells, testosterone action has
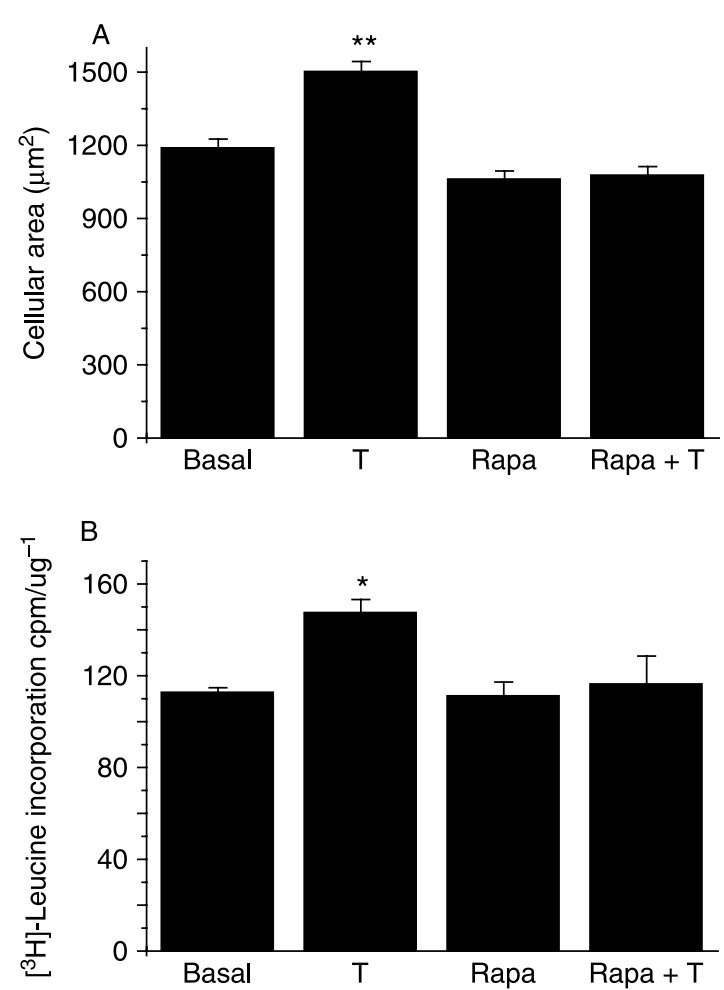

Figure 7 Participation of mTORC1 in the testosterone-induced cardiomyocyte hypertrophy. (Panel A) Cell size was monitored after $48 \mathrm{~h}$ of treatment with testosterone (T, $100 \mathrm{nM}$ ). Cardiomyocytes were incubated with cell tracker green and visualized by confocal microscopy. Cell area in cardiomyocytes grown under control conditions was $\sim 1200 \mu \mathrm{m}^{2}$. Testosterone-induced cellular growth showed a $\sim 26 \%$ increase compared with control cells $(n=100$ cells to each condition). Cell size increase induced by testosterone was blocked in cells pre-incubated with rapamycin (rapa, $20 \mathrm{nM}$ ). (Panel B) Protein synthesis was determined by $\left[{ }^{3} \mathrm{H}\right]$-leucine incorporation. Testosterone increased the amino acid incorporation, which was blocked by rapamycin $(n=4)$. Values are mean \pm S.E.M. ${ }^{*} P<0 \cdot 05, * * P<0 \cdot 01$ compared with the basal value. 
pathways. The PI3K/Akt pathway is also involved in the genesis and progression to a hypertrophic phenotype. Overexpression of either PI3K (subunit p110 $\alpha$; Shioi et al. 2000) or Akt (Condorelli et al. 2002, Shioi et al. 2002), in the heart, produces cardiac hypertrophy. Here, we determined that testosterone activates both ERK1/2 and Akt in cultured cardiomyocytes. However, ERK1/2, but not Akt, is necessary for the testosterone-induced mTORC1/S6K1 axis activation.

Akt overexpression induced cardiac hypertrophy at the molecular and histological levels (Condorelli et al. 2002). Furthermore, Akt null mice were defective in exerciseinduced cardiac hypertrophy (DeBosch et al. 2006). These findings indicated that Akt signaling was indeed important for the physiological growth of the heart. Testosterone activates Akt signaling pathway in prostate cancer cells (Papadopoulou et al. 2008) and in osteoblasts (Kang et al. 2004). In this work, we demonstrate that testosterone rapidly increases Akt phosphorylation in cardiomyocytes. These pathways could participate in the hypertrophic response, survival or metabolism of the cardiomyocytes.

We previously determined that testosterone induces $\mathrm{IP}_{3}$ mediated $\mathrm{Ca}^{2+}$ signals in cultured cardiomyocytes and skeletal muscle cells (Estrada et al. 2003, Vicencio et al. 2006). In skeletal muscle cells, this $\mathrm{Ca}^{2+}$ increase is required for ERK1/2 activation (Estrada et al. 2003). Cardiomyocytes exhibit spontaneous $\mathrm{Ca}^{2+}$ oscillations, which correspond to the excitation-contraction coupling mechanism (Frey \& Olson 2003). Although some evidence indicates participation of $\mathrm{Ca}^{2+}$ signaling on the mTORC1 activation, there are no reports of this participation in cardiac cells. In rat liver epithelial cell lines, S6K1 phosphorylation induced by angiotensin II was prevented by BAPTA-AM (Graves et al. 1997). Lysophosphatidic acid stimulation of Swiss 3 T3 fibroblasts promotes a fast S6K1 activation, which depends on PLC activity and intracellular $\mathrm{Ca}^{2+}$ increase (Willard et al. 2001). In Rat1 fibroblasts expressing the $\alpha_{1 \mathrm{~A}}$-adrenergic receptor, phenylephrine induces mTOR, S6K1, and 4E-BP1 activation dependent on both $\mathrm{Ca}^{2+}$ influx and $\mathrm{Ca}^{2+}$ release (Ballou et al. 2003). However, there are no detailed studies showing which $\mathrm{Ca}^{2+}$ pools are involved in mTOR activation or any evidence describing mTORC1 activation through the $\mathrm{Ca}^{2+} / \mathrm{MEK} / \mathrm{ERK} 1 / 2$ pathway. Our results expand the concept of privileged $\mathrm{Ca}^{2+}$ pools to cardiac cells. In cultured cardiomyocytes, testosterone-induced ERK1/2 phosphorylation was independent of extracellular $\mathrm{Ca}^{2+}$, whereas BAPTA-AM and inhibition of the $\mathrm{IP}_{3}$ pathway blocked the ERK1/2 activation, suggesting the participation of an $\mathrm{IP}_{3^{-}}$ mediated intracellular $\mathrm{Ca}^{2+}$ increase. The mechanisms of $\mathrm{Ca}^{2+}$-mediated ERK1/2 activation remain elusive; however, in cardiac cells a Ras-dependent activation of ERK1/2 by protein kinase C (Chiloeches et al. 1999) has been described. Accordingly, testosterone-induced S6K1 phosphorylation was completely blocked by inhibition of both intracellular $\mathrm{Ca}^{2+}$ increase and the $\mathrm{IP}_{3}$ pathway. Moreover, testosteroneinduced ERK1/2 phosphorylation in cardiomyocytes was inhibited by pretreatment with PTX. These results are in agreement with the inhibition of ERK1/2/mTORC1/S6K1 pathway, by the G-protein inhibitor and with the $\mathrm{Ca}^{2+}$ requirement for ERK1/2 and S6K1 phosphorylation induced by testosterone.

Cardiac hypertrophy is produced in response to several pathophysiological conditions, such as mechanical stretching or neurohumoral deregulation. This process is characterized by increases in cardiomyocyte size and protein synthesis, as well as by the re-expression of various fetal genes (Izumo et al. 1987, 1988, Frey \& Olson 2003). Testosterone induced a hypertrophic pattern in cardiomyocytes, evaluated by three parameters: 1) changes in the expression of $\beta-\mathrm{MHC}$ and SKA, which are well-known cardiac hypertrophy markers, 2) cardiomyocyte size, and 3) protein synthesis assessed by amino acid incorporation. Testosterone induced a significant increase in all three parameters that were blocked by the inhibition of mTORC1. Results suggest that the hypertrophic effects of testosterone on cardiomyocytes involve the mTORC1 pathway. In cardiomyocytes, testosterone action has been explicated only by activation of the intracellular AR (Marsh et al. 1998). We propose that cell growth produced by anabolic steroid hormones requires both androgen receptor (AR) activity and translation control through mTOR signaling pathway. Thus, both mTOR pathway and AR could control protein synthesis by a coordinated mechanism, where mTOR regulates translation and the AR regulates gene expression. However, further experiments are needed to determine the precise role of mTOR on AR signaling and vice versa.

In conclusion, we determined that testosterone activates mTORC1/S6K1 axis through MEK/ERK1/2 and $\mathrm{IP}_{3} / \mathrm{Ca}^{2+}$ signaling. Moreover, testosterone-induced cardiomyocyte hypertrophy was prevented by mTORC1 inhibition. These data collectively support an anabolic mechanism for testosterone prior or parallel to the canonical AR pathway. Thus, the mTORC1/S6K1 pathway might be an important regulator of the metabolic signals for anabolic/ androgenic steroid hormones in the heart.

\section{Declaration of interest}

There is no conflict of interest.

\section{Funding}

This work was supported by Fondo Nacional de Ciencia y Tecnología (FONDECYT) Grant nos. 1060077 and 1090276 (to M E) and Fondo de Investigación Avanzada en Areas Prioritarias (FONDAP) Grant 1501006 (to $\mathrm{M} \mathrm{E}$ and $\mathrm{S} \mathrm{L}$ ). $\mathrm{F} \mathrm{A}$ is a recipient of a doctoral fellowship from Comisión Nacional de Ciencia y Tecnología (CONICYT).

\section{Acknowledgements}

We thank Dr Barbara Ehrlich, Yale University, for the preliminary results. 


\section{References}

Agell N, Bachs O, Rocamora N \& Villalonga P 2002 Modulation of the Ras/Raf/MEK/ERK pathway by $\mathrm{Ca}(2+)$, and calmodulin. Cellular Signalling 14 649-654.

Ballou LM, Jiang YP, Du G, Frohman MA \& Lin RZ $2003 \mathrm{Ca}(2+)-$ and phospholipase D-dependent and -independent pathways activate mTOR signaling. FEBS Letters $\mathbf{5 5 0} 51-56$.

Boluyt MO, Zheng JS, Younes A, Long X, O'Neill L, Silverman H, Lakatta EG \& Crow MT 1997 Rapamycin inhibits alpha 1-adrenergic receptor-stimulated cardiac myocyte hypertrophy but not activation of hypertrophy-associated genes. Evidence for involvement of p70 S6 kinase. Circulation Research 81 176-186.

Bueno OF, De Windt LJ, Tymitz KM, Witt SA, Kimball TR, Klevitsky R, Hewett TE, Jones SP, Lefer DJ, Peng CF et al. 2000 The MEK1-ERK1/2 signaling pathway promotes compensated cardiac hypertrophy in transgenic mice. EMBO Journal $196341-6350$.

Cabral AM, Vasquez EC, Moyses MR \& Antonio A 1988 Sex hormone modulation of ventricular hypertrophy in sinoaortic denervated rats. Hypertension 11 I93-I97.

Condorelli G, Drusco A, Stassi G, Bellacosa A, Roncarati R, Iaccarino G, Russo MA, Gu Y, Dalton N, Chung C et al. 2002 Akt induces enhanced myocardial contractility and cell size in vivo in transgenic mice. PNAS 99 $12333-12338$.

Chen J, Zheng XF, Brown EJ \& Schreiber SL 1995 Identification of an 11-kDa FKBP12-rapamycin-binding domain within the 289-kDa FKBP12-rapamycin-associated protein and characterization of a critical serine residue. PNAS 92 4947-4951.

Chiloeches A, Paterson HF, Marais R, Clerk A, Marshall CJ \& Sugden PH 1999 Regulation of Ras. GTP loading and Ras-Raf association in neonatal rat ventricular myocytes by $G$ protein-coupled receptor agonists and phorbol ester. Activation of the extracellular signal-regulated kinase cascade by phorbol ester is mediated by Ras. Journal of Biological Chemistry 274 19762-19770.

DeBosch B, Treskov I, Lupu TS, Weinheimer C, Kovacs A, Courtois M \& Muslin AJ 2006 Akt1 is required for physiological cardiac growth. Circulation 113 2097-2104.

Estrada M, Espinosa A, Muller M \& Jaimovich E 2003 Testosterone stimulates intracellular calcium release and mitogen-activated protein kinases via a $G$ protein-coupled receptor in skeletal muscle cells. Endocrinology 144 3586-3597.

Estrada M, Uhlen P \& Ehrlich BE $2006 \mathrm{Ca}^{2+}$ oscillations induced by testosterone enhance neurite outgrowth. Journal of Cell Science 119 733-743.

Evans NA 2004 Current concepts in anabolic-androgenic steroids. American Journal of Sports Medicine 32 534-542.

Frey N \& Olson EN 2003 Cardiac hypertrophy: the good, the bad, and the ugly. Annual Review of Physiology 65 45-79.

Gao XM, Wong G, Wang B, Kiriazis H, Moore XL, Su YD, Dart A \& Du XJ 2006 Inhibition of mTOR reduces chronic pressure-overload cardiac hypertrophy and fibrosis. Journal of Hypertension 24 1663-1670.

Graves LM, He Y, Lambert J, Hunter D, Li X \& Earp HS 1997 An intracellular calcium signal activates $\mathrm{p} 70$ but not $\mathrm{p} 90$ ribosomal S6 kinase in liver epithelial cells. Journal of Biological Chemistry 272 1920-1928.

Hannan RD, Jenkins A, Jenkins AK \& Brandenburger Y 2003 Cardiac hypertrophy: a matter of translation. Clinical and Experimental Pharmacology and Physiology 30 517-527.

Izumo S, Lompre AM, Matsuoka R, Koren G, Schwartz K, Nadal-Ginard B \& Mahdavi V 1987 Myosin heavy chain messenger RNA and protein isoform transitions during cardiac hypertrophy. Interaction between hemodynamic and thyroid hormone-induced signals. Journal of Clinical Investigation 79 970-977.

Izumo S, Nadal-Ginard B \& Mahdavi V 1988 Protooncogene induction and reprogramming of cardiac gene expression produced by pressure overload. PNAS 85 339-343.
Kang HY, Cho CL, Huang KL, Wang JC, Hu YC, Lin HK, Chang C \& Huang KE 2004 Nongenomic androgen activation of phosphatidylinositol 3-kinase/Akt signaling pathway in MC3T3-E1 osteoblasts. Journal of Bone and Mineral Research 19 1181-1190.

Kemi OJ, Ceci M, Wisloff U, Grimaldi S, Gallo P, Smith GL, Condorelli G \& Ellingsen O 2008 Activation or inactivation of cardiac Akt/mTOR signaling diverges physiological from pathological hypertrophy. Journal of Cellular Physiology 214 316-321.

Kenessey A \& Ojamaa K 2006 Thyroid hormone stimulates protein synthesis in the cardiomyocyte by activating the Akt-mTOR and $\mathrm{p} 70 \mathrm{~S} 6 \mathrm{~K}$ pathways. Journal of Biological Chemistry 281 20666-20672.

Kuzman JA, O'Connell TD \& Gerdes AM 2007 Rapamycin prevents thyroid hormone-induced cardiac hypertrophy. Endocrinology 148 3477-3484.

Malhotra A, Buttrick P \& Scheuer J 1990 Effects of sex hormones on development of physiological and pathological cardiac hypertrophy in male and female rats. American Journal of Physiology 259 H866-H871.

Marsh JD, Lehmann MH, Ritchie RH, Gwathmey JK, Green GE \& Schiebinger RJ 1998 Androgen receptors mediate hypertrophy in cardiac myocytes. Circulation 98 256-261.

McMullen JR, Sherwood MC, Tarnavski O, Zhang L, Dorfman AL, Shioi T \& Izumo S 2004 Inhibition of mTOR signaling with rapamycin regresses established cardiac hypertrophy induced by pressure overload. Circulation 109 3050-3055.

Muller M, van der Schouw YT, Thijssen JH \& Grobbee DE 2003 Endogenous sex hormones and cardiovascular disease in men. Journal of Clinical Endocrinology and Metabolism 88 5076-5086.

Nahrendorf M, Frantz S, Hu K, von zur Muhlen C, Tomaszewski M, Scheuermann H, Kaiser R, Jazbutyte V, Beer S, Bauer W et al. 2003 Effect of testosterone on post-myocardial infarction remodeling and function. Cardiovascular Research 57 370-378.

Papadopoulou N, Charalampopoulos I, Anagnostopoulou V, Konstantinidis G, Foller M, Gravanis A, Alevizopoulos K, Lang F \& Stournaras C $2008 \mathrm{Membrane}$ androgen receptor activation triggers down-regulation of PI-3K/Akt/NF-kappaB activity and induces apoptotic responses via Bad. FasL and caspase-3 in DU145 prostate cancer cells. Molecular Cancer 788 .

Proud CG 2004 Ras, PI3-kinase and mTOR signaling in cardiac hypertrophy. Cardiovascular Research 63 403-413.

Richardson CJ, Schalm SS \& Blenis J 2004 PI3-kinase and TOR: PIKTORing cell growth. Seminars in Cell and Developmental Biology 15 147-159.

Rolfe M, McLeod LE, Pratt PF \& Proud CG 2005 Activation of protein synthesis in cardiomyocytes by the hypertrophic agent phenylephrine requires the activation of $\mathrm{ERK}$ and involves phosphorylation of tuberous sclerosis complex 2 (TSC2). Biochemical Journal 388 973-984.

Shioi T, Kang PM, Douglas PS, Hampe J, Yballe CM, Lawitts J, Cantley LC \& Izumo S 2000 The conserved phosphoinositide 3-kinase pathway determines heart size in mice. EMBO Journal 19 2537-2548.

Shioi T, McMullen JR, Kang PM, Douglas PS, Obata T, Franke TF, Cantley LC \& Izumo S 2002 Akt/protein kinase B promotes organ growth in transgenic mice. Molecular and Cellular Biology 22 2799-2809.

Shioi T, McMullen JR, Tarnavski O, Converso K, Sherwood MC, Manning WJ \& Izumo S 2003 Rapamycin attenuates load-induced cardiac hypertrophy in mice. Circulation 107 1664-1670.

Simm A, Schluter K, Diez C, Piper HM \& Hoppe J 1998 Activation of p70(S6) kinase by beta-adrenoceptor agonists on adult cardiomyocytes. Journal of Molecular and Cellular Cardiology 30 2059-2067.

Takano H, Komuro I, Zou Y, Kudoh S, Yamazaki T \& Yazaki Y 1996 Activation of p70 S6 protein kinase is necessary for angiotensin II-induced hypertrophy in neonatal rat cardiac myocytes. FEBS Letters 379 255-259.

Thimmaiah KN, Easton JB, Germain GS, Morton CL, Kamath S, Buolamwini JK \& Houghton PJ 2005 Identification of N10-substituted phenoxazines as potent and specific inhibitors of Akt signaling. Journal of Biological Chemistry 280 31924-31935. 
Vicencio JM, Ibarra C, Estrada M, Chiong M, Soto D, Parra V, Diaz-Araya G, Jaimovich E \& Lavandero S 2006 Testosterone induces an intracellular calcium increase by a nongenomic mechanism in cultured rat cardiac myocytes. Endocrinology 147 1386-1395.

Wang L \& Proud CG 2002 Ras/Erk signaling is essential for activation of protein synthesis by $\mathrm{Gq}$ protein-coupled receptor agonists in adult cardiomyocytes. Circulation Research 91 821-829.

Wang X \& Proud CG 2007 Methods for studying signal-dependent regulation of translation factor activity. Methods in Enzymology 431 113-142.
Willard FS, Berven LA \& Crouch MF 2001 Lysophosphatidic acid activates the 70-kDa S6 kinase via the lipoxygenase pathway. Biochemical and Biophysical Research Communications 287 607-613.

Received in final form 20 May 2009

Accepted 26 May 2009

Made available online as an Accepted Preprint 26 May 2009 